Brazilian Journal

of Chemical

\title{
DEVELOPMENT OF A FLUIDIZED BED SYSTEM FOR ADSORPTION OF PHENOL FROM AQUEOUS SOLUTIONS WITH COMMERCIAL MACROPOROUS RESINS
}

\author{
R. A. Corrêa ${ }^{1 *}$, L. A. Calçada ${ }^{2}$ and R. P. Peçanha ${ }^{3}$ \\ ${ }^{1}$ Instituto de Engenharia Nuclear (DIQN / SETEQ), CNEN / MCT, \\ Cidade Universitária, Ilha do Fundão, CEP: 21945 970, \\ Rio de Janeiro - RJ, Brasil \\ E-mail: racorrea@ien.gov.br \\ ${ }^{2}$ Departamento de Engenharia Química/UFRRJ \\ E-mail: calcada@ufrrj.br \\ ${ }^{3}$ Departamento de Engenharia Química, Escola de Química/UFRJ, \\ Phone: +(55) (21) 2562 7633, Fax: +(55) (21) 25627631 \\ E-mail: pecanha@eq.ufrj.br
}

(Received: May 16, 2006 ; Accepted: October 30, 2006)

\begin{abstract}
This work is related to removal of phenol from wastewaters by adsorption onto polymeric resins, a current alternative to activated carbon. A closed circuit, bench-scale liquid fluidized bed system was developed for this purpose. Phenol aqueous solutions with initial concentrations in the range of 0.084 to 0.451 $\mathrm{kg} / \mathrm{m}^{3}$ were used to fluidize small permeable capsules of stainless steel screen containing a commercial resin at $308 \mathrm{~K}$. Experiments were carried out using a fluidizing velocity $20 \%$ above that of the minimum fluidization of the capsules. Typically, 30 passages of the liquid volume circulating through the bed were required to reach a quasi-equilibrium concentration of phenol in the treated effluent. A simple batch adsorption model using the Freundlich isotherm successfully predicted final phenol concentrations. Suspended solids, often present in residual waters and a common cause of fixed bed clogging, were simulated with wood sawdust.

Keywords: Phenol adsorption; Fluidized beds; Macroporous resins.
\end{abstract}

\section{INTRODUCTION}

Phenols comprise a large category of organic compounds highly toxic for the vast majority of known forms of life, including humans. The toxicity of these substances is mainly related to the aromatic ring and to a lesser extent to their acid properties. The main chemical is phenol $\left(\mathrm{C}_{6} \mathrm{H}_{5} \mathrm{OH}, \mathrm{K}_{\mathrm{a}}=1.0 \times\right.$ $10^{-10}$ at $25^{\circ} \mathrm{C}$ ), present in the wastewater of many important industries, like those of dyes, explosives, adhesives, emulsifiers, pesticides, insecticides, detergents, etc. (Wagner and Schulz, 2001).
The solubility of phenol in water at $288 \mathrm{~K}$ is appreciable: $82 \mathrm{~kg} / \mathrm{m}^{3}$. Consequently, without rigorous emission control, the phenol concentration in wastewaters will exceed legal limits quite easily.

The most important phenol recovery method is adsorption onto activated carbon or polymeric resins. Fixed beds are used for large-scale operation while mechanically agitated suspensions are preferred for medium/small-scale ones (Cooney, 1999). Regeneration and reutilization of adsorbent is a key economic factor in both cases (Wagner and Schulz, 2001; Zha et al., 1994).

*To whom correspondence should be addressed 
The chemical nature of phenol adsorption on activated carbon makes its regeneration more costly than that of polymeric resins, where physical adsorption prevails. Also, activated carbon granules are easily friable, producing fine particles on handling, transportation and in shocks with mixer blades and chicanes. These can either be entrained from the system carrying adsorbed molecules to the receiving body or worse, in the case of fixed beds, migrate internally, clogging the porous structure of the bed. On the other hand, due to crosslinking, beads of polymer resins are strong and reasonably elastic. According to Paleos (1969), all aspects considered (including the marked difference between the unit costs of each material), the use of resins is economically more advantageous then the use of activated carbon.

Another aspect to be considered is that wastewaters always contain suspended solids (e.g., fibers, waxes and gums) which clog fixed beds, requiring frequent backwashing or fluidization to dislodge the foreign material (Veeraraghavan et al., 1989).

Other problems typical of fixed beds are dead zones, gas/vapor pockets and channeling. Additionally, pressure drops in fixed beds are roughly proportional to the square of the superficial fluidizing velocity, causing relatively high pumping costs (Kunii and Levenspiel, 1969).

Table 1 compares fixed beds, mechanically agitated suspensions and fluidized beds as alternatives for contacting adsorbents and solutions.

Motivated by the above mentioned operational problems of fixed beds and mechanically agitated suspensions of activated carbon granules, this work is aimed at the development of a liquid fluidized bed system for adsorption of phenol from wastewaters using polymeric resins.

Table 1: Comparison of equipment for contacting adsorbents and solutions

\begin{tabular}{|l|c|c|c|}
\hline Characteristic Method & Fixed bed of adsorbent & $\begin{array}{c}\text { Suspended adsorbent in } \\
\text { agitated liquid }\end{array}$ & $\begin{array}{c}\text { Fluidization of } \\
\text { encapsulated adsorbent }\end{array}$ \\
\hline Attrition & No & Yes & No \\
Clogging & Yes & Yes & No \\
Dead zones & Yes & Yes & No \\
Uniform temperature & No & Yes & Yes \\
Uniform concentration & No & Yes & Yes \\
\hline
\end{tabular}

\section{THEORY}

Like other unit operations dependent on the mass transfer of individual species (e.g., distillation, absorption, stripping, etc.), the design of adsorption equipment relies on equilibrium data, represented by isotherms, as well as on transient mass balances for the adsorbate, represented by the so-called breakthrough curves (McCabe et al., 2001).

\section{Isotherms and Models}

In adsorption systems, adsorbate is continuously transferred from the carrier fluid to the adsorbent material. For this to happen, the actual concentration of adsorbate on the adsorbent (q) should be smaller than the equilibrium concentration $\left(\mathrm{q}^{*}\right)$ for the same concentration of adsorbate in the fluid(C). Thus $\mathrm{q}^{*}=$ $\mathrm{f}$ (C) represents equilibrium. Alternatively, equilibrium can be expressed as $C^{*}=g(q)$ where $C^{*}$ is the concentration of adsorbate in the fluid that would be in equilibrium with $\mathrm{q}$.
In accordance with $\mathrm{Ku}$ and Lee (2000), Navarro and Mijangos (1995), Mijangos and Navarro (1995) and Gusler et al. (1993), adsorption equilibria were described in this work with the Freundlich isotherm:

$\mathrm{q}^{*}=\mathrm{k} \quad \mathrm{C}^{\mathrm{n}}$

where $\mathrm{k}$ and $\mathrm{n}$ are empirical constants. Notice that $\mathrm{k}$ units depend on $\mathrm{q}^{*}$ and $\mathrm{C}$ units, while $\mathrm{n}$ is dimensionless.

\section{Breakthrough Curves and Models}

Breakthrough curves represent the time profile for saturation of a given amount of an adsorbent structured as a fixed bed with a given solution of an adsorbate forced through this bed at a constant rate and fixed temperature. In spite of being fully empirical and dependent on almost all variables involved, breakthrough curves serve two purposes: (a) to decide whether the adsorbent is efficient for the required separation and (b) to establish the break 
point (process interruption), based on some criterion, either technical, economic or legal (Knaebel, 1999).

Breakthrough curves can be developed based on the basis of transient mass balance for the adsorbate in an infinitesimal volume of adsorbent fixed bed continuously percolated by a fluid carrying the adsorbate. The following hypotheses are adopted:

- temperature is constant: the adsorption heat, which increases the system temperature, is neglected. The lower the concentration of the adsorbate in the fluid in the feed stream, the smaller the temperature rise will be;

- flow rate is constant: the lower the concentration of the adsorbate in the fluid in the feed stream, the smaller the effect of adsorption on the flow rate will be. Flow transients characteristic of large-scale plants are also prohibited;

- interstitial velocity profile is plug flow: in addition to the previous hypothesis this one also requires a uniform bed porosity;

- adsorbate is not involved in chemical reactions: this is equivalent to saying that the adsorbate fed is either adsorbed or leaves the system in the effluent;

- adsorbate is not dispersed: all types of mixing effects (convective, diffusive and eddy) are prohibited within the fixed bed.

Under these idealized conditions, the adsorbate mass conservation in the system can be expressed by the following equation (Hines and Maddox, 1985):

$\mathrm{D}_{\mathrm{Z}} \frac{\partial^{2} \mathrm{C}}{\partial \mathrm{z}^{2}}-\mathrm{u} \frac{\partial \mathrm{C}}{\partial \mathrm{z}}=\frac{\partial \mathrm{C}}{\partial \mathrm{t}}+\frac{(1-\varepsilon)}{\varepsilon} \frac{\partial \mathrm{C}_{\mathrm{a}}}{\partial \mathrm{t}}$

where $D_{Z}$ is the effective axial diffusion coefficient of the adsorbate, $\mathrm{z}$ is axial distance, $\mathrm{u}$ is the interstitial fluid velocity, $\mathrm{t}$ is time, $\varepsilon$ is the bed porosity and $\mathrm{C}_{\mathrm{a}}$ is the concentration of adsorbate on the adsorbent.

Equation (4) can be rewritten as

$\mathrm{D}_{\mathrm{Z}} \varepsilon \frac{\partial^{2} \mathrm{C}}{\partial \mathrm{z}^{2}}-\mathrm{u} \varepsilon \frac{\partial \mathrm{C}}{\partial \mathrm{z}}=\varepsilon \frac{\partial \mathrm{C}}{\partial \mathrm{t}}+\rho_{\mathrm{a}}(1-\varepsilon) \frac{\partial \mathrm{q}}{\partial \mathrm{t}}$

where $\rho_{\mathrm{a}}$ is the density of the adsorbent material and $\mathrm{q}$, defined previously, is the actual concentration of adsorbate in the adsorbent.

As a matter of fact $\rho_{\mathrm{a}}(1-\varepsilon)$ is the density of the adsorbent bed, symbolized simply by $\rho$. Thus equation (3) becomes

$$
\mathrm{D}_{\mathrm{Z}} \varepsilon \frac{\partial^{2} \mathrm{C}}{\partial \mathrm{z}^{2}}-\mathrm{u} \varepsilon \frac{\partial \mathrm{C}}{\partial \mathrm{z}}=\varepsilon \frac{\partial \mathrm{C}}{\partial \mathrm{t}}+\rho \frac{\partial \mathrm{q}}{\partial \mathrm{t}}
$$

Since diffusion is generally a slow process compared to the bulk flow present in fixed bed adsorption systems, the first term in equation (4) can be neglected giving:

$\varepsilon \frac{\partial \mathrm{C}}{\partial \mathrm{t}}+\mathrm{u} \varepsilon \frac{\partial \mathrm{C}}{\partial \mathrm{z}}+\rho \frac{\partial \mathrm{q}}{\partial \mathrm{t}}=0$

The initial and boundary conditions associated with equation (5) are

$$
\begin{aligned}
& \mathrm{t}=0, \quad \mathrm{C}=0 \quad(0 \leq \mathrm{z} \leq \mathrm{H}) \\
& \mathrm{t}>0, \quad \mathrm{C}=\mathrm{C}_{\mathrm{F}} \quad(\mathrm{z}=0)
\end{aligned}
$$

where $\mathrm{H}$ is the height of the adsorbent bed and $\mathrm{C}_{\mathrm{F}}$ is the concentration of adsorbate in the liquid in the bed feed stream.

An additional simplification regards the third term in equation (5), the adsorption rate of adsorbate. It can be expressed in terms of an overall liquid phase mass transfer coefficient, $\mathrm{K}_{\mathrm{L}}$; the interfacial mass transfer area per unit volume of bed, a; and the deviation from equilibrium concentration in the fluid, as follows (Sherwood et al., 1975):

$\rho \frac{\partial \mathrm{q}}{\partial \mathrm{t}}=\varepsilon \quad \mathrm{K}_{\mathrm{L}} \quad \mathrm{a}\left(\mathrm{C}-\mathrm{C}^{*}\right)$

Following the approach of Chern and Chien (2002), which is based on the nonlinear wave propagation theory, the concept of adjusted time, $\tau$, is introduced as follows:

$$
\tau=\mathrm{t}-\frac{\mathrm{z}}{\mathrm{u}_{\mathrm{w}}}
$$

where $\mathrm{u}_{\mathrm{w}}$ is the adsorbate concentration wave velocity. According to this theory the shape of the concentration wave is constant as it travels through the adsorbent bed.

Substituting equation (9) into equation (5) results in:

$$
\left(1-\frac{\mathrm{u}}{\mathrm{u}_{\mathrm{w}}}\right) \frac{\mathrm{dC}}{\mathrm{d} \tau}+\frac{\rho}{\varepsilon} \frac{\mathrm{dq}}{\mathrm{d} \tau}=0
$$


which is clearly independent of $\tau$.

The following boundary condition holds:

$\mathrm{C}=\mathrm{C}_{\mathrm{F}}, \quad \mathrm{q}=\mathrm{q}_{\mathrm{F}}^{*}$

where $\mathrm{q}_{\mathrm{F}}^{*}$ is the concentration of adsorbate on the solid that would be in equilibrium with $\mathrm{C}_{\mathrm{F}}$.

Equation (10) can then be integrated to give

$\frac{\mathrm{q}}{\mathrm{q}_{\mathrm{F}}^{*}}=\frac{\mathrm{C}}{\mathrm{C}_{\mathrm{F}}}$

In terms of the adjusted time, equation (8) becomes

$\rho \frac{\partial \mathrm{q}}{\partial \tau}=\varepsilon \quad \mathrm{K}_{\mathrm{L}} \quad \mathrm{a}\left(\mathrm{C}-\mathrm{C}^{*}\right)$

Since $C^{*}=g(q)$ and with $q$ given by equation (12) and assuming further that $\mathrm{K}_{\mathrm{L}}$ a is constant, equation (13) can be integrated between suitable limits to give

$\mathrm{t}=\mathrm{t}_{1 / 2}+\frac{\rho \mathrm{q}_{\mathrm{F}}^{*}}{\varepsilon \mathrm{K}_{\mathrm{L}} \mathrm{aC}_{\mathrm{F}}} \int_{\mathrm{C}_{\mathrm{F}} / 2}^{\mathrm{C}} \frac{1}{\mathrm{C}-\mathrm{g}_{1}\left(\mathrm{q}_{\mathrm{F}}^{*} \mathrm{C} / \mathrm{C}_{\mathrm{F}}\right)} \mathrm{dC}$

where $t_{1 / 2}$ is the time required for the concentration of adsorbate in the bed effluent to rise to $\mathrm{C}_{\mathrm{F}} / 2$.

If the Freundlich isotherm, equation represents the equilibrium data, equation becomes

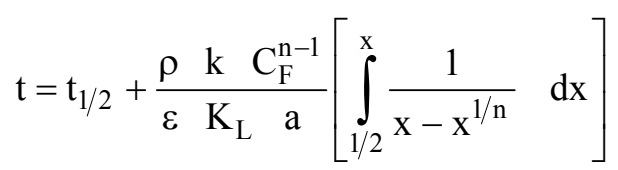

where $\mathrm{x}$ is the normalized, or relative, concentration of adsorbate in the bed effluent, defined as $\mathrm{x}=\mathrm{C} / \mathrm{C}_{\mathrm{F}}$.

Equation (15) represents a model of breakthrough curve using the Freundlich isotherm. The parameter $t_{1 / 2}$ is obtained directly from the experimental data, while $\mathrm{K}_{\mathrm{L}}$ a is determined from the known slope of the tangent to the curve $\mathrm{x}$ versus $\mathrm{t}$ at $\mathrm{x}=0.5$, as follows. The integral in equation (15) is solved, giving an expression for $\mathrm{x}$ as a function of $\mathrm{t}$, whose derivative in relation to $t$ is the general curve slope. Since the slope at $\mathrm{x}=0.5$ is known from experiments, $\mathrm{K}_{\mathrm{L}}$ a can be computed:

$\left(\frac{\mathrm{dx}}{\mathrm{dt}}\right)_{\mathrm{x}=0.5}=\frac{\varepsilon \mathrm{K}_{\mathrm{L}} \quad \mathrm{a}}{\rho \mathrm{k} \mathrm{C}_{\mathrm{F}}^{\mathrm{n}-1}}\left(\mathrm{x}-\mathrm{x}^{1 / \mathrm{n}}\right)$

The breakthrough curve predicted by equation (15) will be checked against our own experimental data.

\section{EXPERIMENTAL AND MODELING}

From here on, when the specificity of the text allows, we prefer to use the words "phenol," "resin" and "aqueous solution" instead of, respectively, "adsorbate," "adsorbent" and "fluid," which are generic.

\section{Adsorbent}

The literature survey showed that the commercial resin Amberlite $\mathrm{XAD}^{\mathrm{TM}} 4$ (Rohm and Haas Co.), was the best adsorbent for phenol from aqueous solutions. According to Fox (1978) the resin, which is a copolymer of styrene and divinylbenzene, has been tested for up to 1300 cycles (or two years) of adsorption and regeneration, with negligible loss of adsorptive capacity. Table 2 shows the relevant characteristics of the $\mathrm{XAD}^{\mathrm{TM}} 4$ resin used in this work.

Since fluidization was our main concern, the resin density, size distribution and particle shape were the first characterizations made.

Mean density was quantified with an ordinary density bottle. Since the resin absorbs water, prior to measurement of density, samples were soaked in water so as to give its real density in the fluidized bed. Next, the resin was quickly dried and only then measurements were made.

The resin particle size distribution was determined with a set of standard sieves. Since resin particles could swell upon absorbing water, samples were initially soaked in water and then wet sieved. The resin was characterized by the Sauter mean particle size $\left(D_{S}\right)$.

Figure 1 is illustrative of a typical sample of $\mathrm{XAD}^{\mathrm{TM}} 4$ resin. Notice the spherical shape of particles and the variable size. 
Table 2: Characteristics of $\mathrm{XAD}^{\mathrm{TM}} \mathbf{4}$ resin (Rohm and Haas Co., 2001)

\begin{tabular}{|l|c|}
\hline Visual aspect & White, translucent \\
\hline Specific gravity & $1.01-1.03$ \\
Particle size (harmonic mean ), mm & $0.49-0.69$ \\
Specific surface area, $\mathrm{m}^{2} / \mathrm{g}$ & 750 \\
Porosity & 0.50 \\
Pore mean diameter, $\AA$ & 100 \\
\hline
\end{tabular}

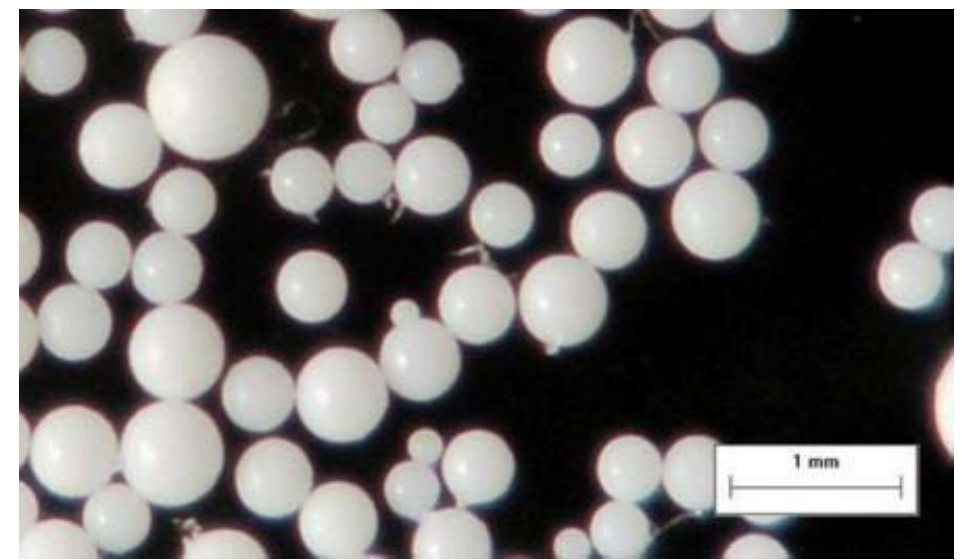

Figure 1: Particles of XAD 4 resin (Rohm and Haas Co.)

\section{Isotherms}

Isotherms were established at $308 \mathrm{~K}$ using a thermostatic agitated bath (Dubnoff, Mod. 304, Nova Ética), with various initial concentrations of phenol tested simultaneously. Phenol P.A. (Vetec Química) was dissolved in distilled and deionized water to give a solution with a concentration around $41.36 \mathrm{~kg} / \mathrm{m}^{3}$. The solution served as a supplier batch for further dilution as required. Conical flasks of $2.5 \times 10^{-4} \mathrm{~m}^{3}$ containing $5.0 \times 10^{-4} \mathrm{~kg}$ of resin and $5.0 \times 10^{-5} \mathrm{~m}^{3}$ of aqueous phenol solution at various initial concentrations were shaken during 14 days. The equilibrium concentration of phenol on the solid phase, $\mathrm{q}^{*}$, was calculated with the equation:

$$
\mathrm{q}^{*}=\left(\mathrm{C}_{\mathrm{i}}-\mathrm{C}^{*}\right) \frac{\mathrm{V}_{\text {liq }}}{\mathrm{M}}
$$

where $C_{i}$ and $C^{*}$ are respectively the initial and the equilibrium concentration of phenol in the liquid, $\mathrm{V}_{\text {liq }}$ is the initial volume of liquid and $M$ is the initial mass of resin. Notice that equation (17) is approximate, since the volume of adsorbed phenol was negligible in relation to $\mathrm{V}_{\text {liq }}$. Lower values of
$\mathrm{C}_{\mathrm{i}}$ and $\mathrm{M}$, improve this approximation. Values of $\mathrm{C}^{*}$ were determined using a UV spectrophotometer (GBC Scientific Equipment, mod. $918 \mathrm{UV}$ ) at a wavelength of $2.693 \times 10^{-7} \mathrm{~m}$.

\section{Breakthrough Curves}

A sketch of the equipment used to establish the breakthrough curves is shown in Figure 2.

The resin was packed in a vertical glass tube with an internal diameter of $1.3 \times 10^{-2} \mathrm{~m}$, supported on a porous sintered glass plate fixed to the tube walls. Phenol solution from the supplier batch was diluted to $0.470 \mathrm{~kg} / \mathrm{m}^{3}$, forming the bed feed. The solution was forced downward through the fixed bed by means of a positive displacement pump with a controllable flow rate (Milton-Roy, mod. LMI). After suitable dilutions, the phenol concentration in the bed effluent was determined by UV spectrophotometry, as already mentioned. The working temperature was $299 \mathrm{~K}$.

The main operational variable of adsorption equipment is the flow rate. Its effects on the breakthrough curves were studied in this work by changing the pump set points of stroke volume and pitch. 


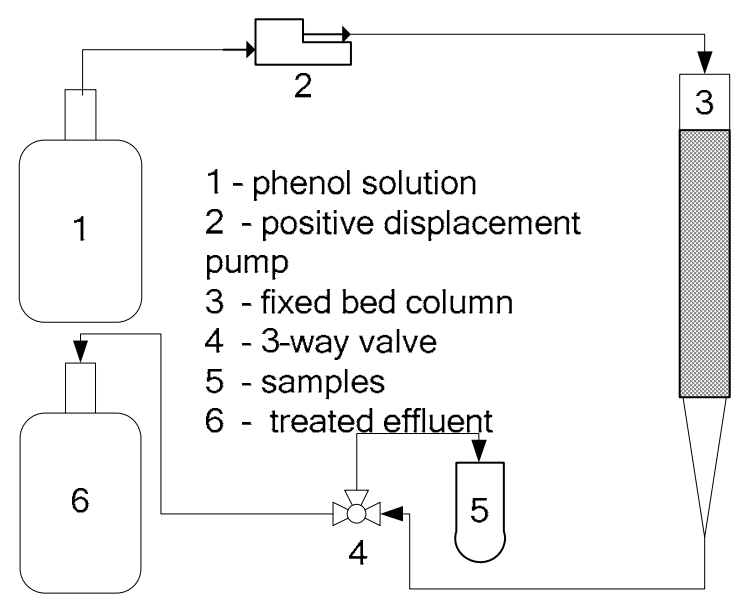

Figure 2: Bench-scale fixed bed of resin and ancillaries

\section{Resin Structured Particles}

Early experiments with the resin $\mathrm{XAD}^{\mathrm{TM}} 4$ showed that after soaking in water, the density of the beads was just above that of water, resulting in very small values for the minimum fluidizing velocity. This fact posed a serious limitation to the fluidization of the resin with water, restricting fluidizing velocities to figures slightly higher than the minimum fluidizing velocity so as to avoid elutriation of the finer resin beads present.

Considering that typical chemical industries produce high wastewater flow rates, the transversal area required to process them in such fluidized beds would be correspondingly large and in most cases probably unviable economically.

To circumvent this limitation a series of ideas were tested, all of them based on fixation or encapsulation of resin particles on a denser support so as to increase the minimum fluidizing velocity. After many attempts it was found that resin could be confined inside small cylindrical capsules (diameter $=0.008 \mathrm{~m}$, length $=0.010 \mathrm{~m}$ ) of stainless steel screen, 42 mesh (opening $=3.54 \times 10^{-4} \mathrm{~m}$ ). The original resin was sieved to remove particles smaller than 42 mesh, guaranteeing that none would escape from the capsules during fluidization. Figure 3 illustrates a fully assembled capsule.

The amount of resin in a single capsule was approximately $1.00 \times 10^{-4} \mathrm{~kg}$, resulting in a relatively loose bed occupying roughly half of the capsule volume. This would allow the resin particles to move around inside the capsule during fluidization, improving the mass transfer of adsorbate towards them. A total of 406 capsules were handcrafted for the tests.

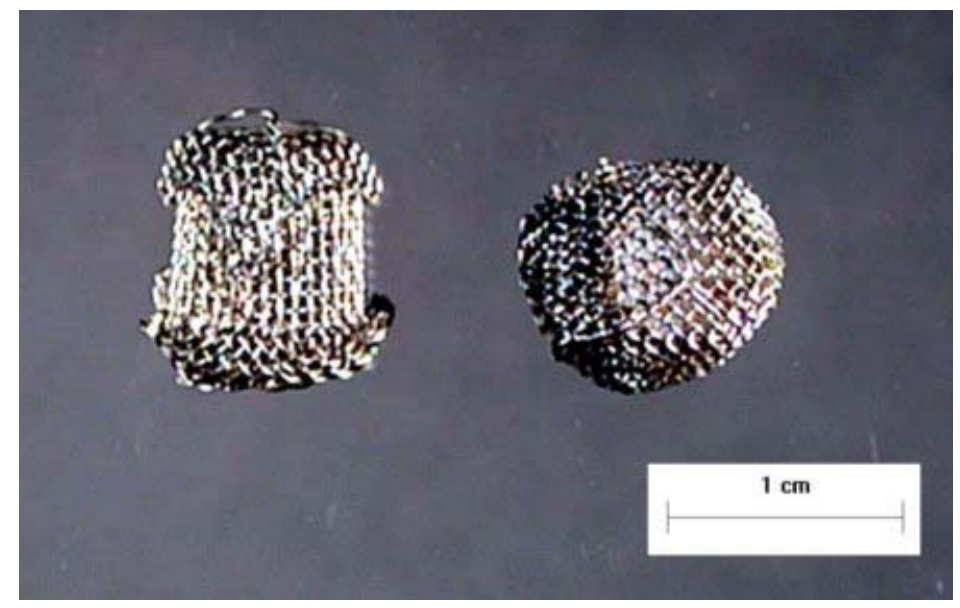

Figure 3: Capsules of stainless steel screen, 42 mesh 


\section{Fluidized Bed}

Fluidization experiments were carried out in the bench-scale equipment shown in Figure 4.

The bed was contained in a vertical glass tube (ID $=0.065 \mathrm{~m})$. The distributor was a $0.013 \mathrm{~m}$ thick fixed bed of polypropylene pellets (mean size = $0.003 \mathrm{~m}$ ), tightly secured between two stainless steel screens, mesh 42 , adapted to the tube by means of flanges. To avoid jetting through the distributor passages, the plenum was packed with glass spheres (mean diameter $=0.002 \mathrm{~m}$ ), which worked as a calming section. The equipment was provided with a single deposit for the fluidizing liquid, which was continuously recycled through the system by means of a centrifugal pump (DANCOR, 372.85 W). We shall call the above-described system a closed circuit fluidized bed (CCFB), not to be confused with the well-known circulating fluidized bed (CFB), mainly used for the combustion of low-grade coals. Flow rates were measured by a calibrated rotameter on the bed feed line. A needle valve on the rotameter feed line allowed good control over the operational flow rate.

The minimum fluidization velocity of the bed of capsules, $U_{\mathrm{m}}$, was determined via the classic plot of bed height $(\mathrm{H})$ versus superficial velocity $\left(\mathrm{v}_{0}\right)$ for decreasing flow rates of water at $308 \mathrm{~K}$.
Seven initial concentrations of phenol in water were tested: $8.4 \times 10^{-5}, 1.72 \times 10^{-4}, 2.24 \times 10^{-4}$, $2.84 \times 10^{-4}, 3.56 \times 10^{-4}, 4.37 \times 10^{-4}$ and $4.51 \times 10^{-4}$ $\mathrm{kg} / \mathrm{m}^{3}$, for a constant flow rate of $4.2 \times 10^{-4} \mathrm{~m}^{3} / \mathrm{s}$. All experiments were carried out at $308 \mathrm{~K}$ using a fluidizing velocity equal to $1.20 \mathrm{U}_{\mathrm{mf}}$. The circulating volume of phenol aqueous solution was approximately $0.010 \mathrm{~m}^{3}$. Liquid samples were taken from the tank at five minute intervals and phenol concentration, $\mathrm{C}$, was measured using UV spectrophotometry as before. The profile $\mathrm{C}$ versus $\mathrm{t}$ for each run showed that a near equilibrium condition was reached after around 20 minutes. To get closer to equilibrium, runs were stopped after 40 minutes. This corresponded roughly to 100 passages of the liquid through the fluidized bed.

To obtain a motion pattern for the capsules during fluidization, tests were filmed with a digital camera. Two spray-painted capsules, one red and one white, were used as tracers. It was found that the capsules circulated in the bed in a tumbling manner. The capsules tended to shoot up when very close to the bed walls and fall down when close to the center. Due to the up-and-down tumbling motion and liquid flow across the screens of the capsules, the resin beads inside them were most certainly under intense agitation. Figure 5 shows a photograph of the fluidized bed during test with the tracer particles.

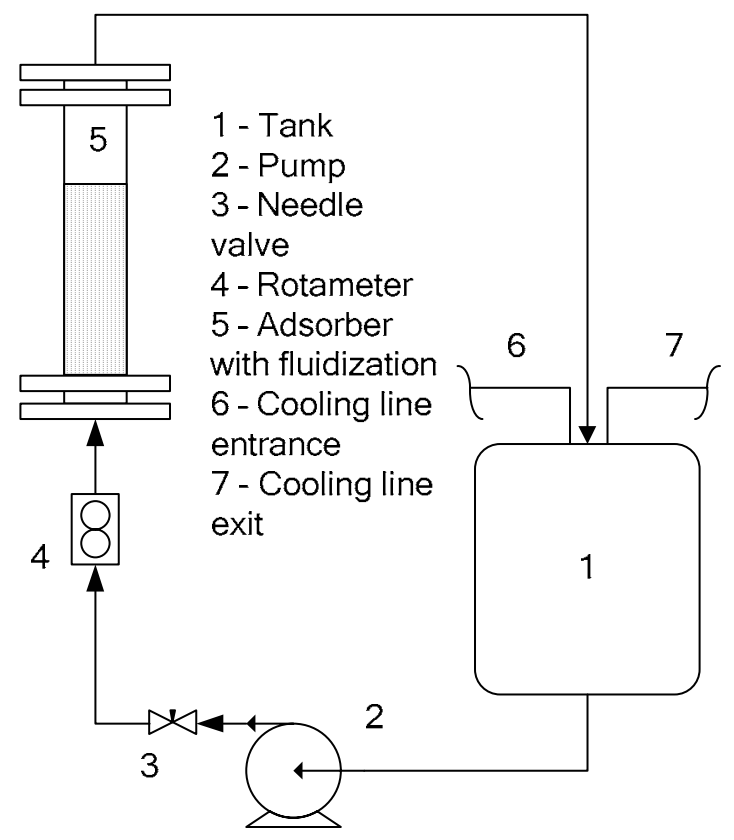

Figure 4: Fluidized bed of capsules and ancillaries 


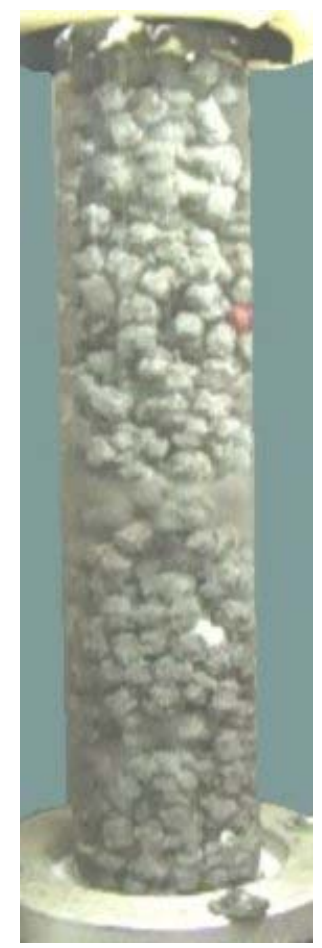

Figure 5: Fluidized bed of capsules during testing showing tracer particles

Suspended solids, a common cause of fixed bed clogging, were simulated with wood sawdust with mesh sizes in the range of 16 to 28 , suspended in water at a concentration of $1.3 \mathrm{~kg} / \mathrm{m}^{3}$. The smallest dust particle found was roughly 1.7 times coarser than the opening of the capsules'stainless steel screen (42 mesh).

The closed circuit fluidized bed (CCFB) was adequately modeled as stirred batch adsorption equipment. The intense pump recycling rate produces similar mixing effects as those of a mechanical device, which supports this strategy.

It is well established that adsorption rates are generally fast higher than other rates (e.g., diffusion of mass and heat) in such systems. Physical adsorption, the topic of this work, is particularly very fast. On this basis it will be assumed that at any time during adsorption, a condition close to equilibrium is established in the vicinity of the adsorbent surface. In this case, adsorption isotherms can be coupled to the overall mass balance of phenol, equation (17).

Notice that $\mathrm{C}$ in the Freundlich isotherm, equation (1), is the same as the equilibrium concentration represented by $\mathrm{C}^{*}$ in equation (17). Eliminating $\mathrm{q}^{*}$ between these two equations and retaining the starred symbol, a transcendental equation in $\mathrm{C}^{*}$ is found, which requires a numerical method of solution:

$$
C^{* n}+\alpha \quad C^{*}+\beta=0
$$

where

$$
\alpha=\frac{\mathrm{V}_{\text {liq }}}{\mathrm{M} \mathrm{k}}
$$

and

$$
\beta=-\frac{\mathrm{V}_{\text {liq }} \mathrm{C}_{\mathrm{i}}}{\mathrm{M} \mathrm{k}}
$$

Equations (18), (19) and (20) correspond to a model for the adsorption process whose predictive power will be tested against our own data.

\section{RESULTS AND DISCUSSION}

\section{Adsorbent}

Dry $\mathrm{XAD}^{\mathrm{TM}} 4$ resin is less dense than water. However, due to its macro porous structure, the resin absorbs water becoming a little denser than water itself, a condition that prevailed in all tests with fixed or fluidized beds. Wet density measurements were 
made in triplicate. The average value was $\rho_{\mathrm{a}}=1060$ $\mathrm{kg} / \mathrm{m}^{3}$.

The resin particle size distribution was established with standard sieves, resulting in a monomodal pattern. The Sauter mean size was $D_{S}$ $=5.4 \times 10^{-8} \mathrm{~m}$, well within the particle size range ascribed to $\mathrm{XAD}^{\mathrm{TM}} 4$ by Rohm and Haas Co. (2001).

\section{Isotherms}

Data on adsorption equilibrium at $308 \mathrm{~K}$ are shown in Figure 6, together with curves adjusted via the Freundlich isotherm model.

Clearly the Freundlich model fitted the data very satisfactorily, in full agreement with the findings of various researchers quoted previously.

The parameters of the Freundlich model were determined by nonlinear regressions of data at $308 \mathrm{~K}$ with the following results: $\mathrm{k}=0.05 \mathrm{~kg}_{\mathrm{p}}^{1-\mathrm{n}} \mathrm{m}_{\mathrm{s}}^{3 \mathrm{n}} / \mathrm{kg}_{\mathrm{r}}, \mathrm{n}=$ 0.59 and $\mathrm{r}^{2}=0.975$.

In addition to the finite bath experiments, blank tests, i.e., without the resin, were carried out to check for phenol photodegradation and/or evaporation. After fourteen days, no measurable variation in phenol concentration was detected.

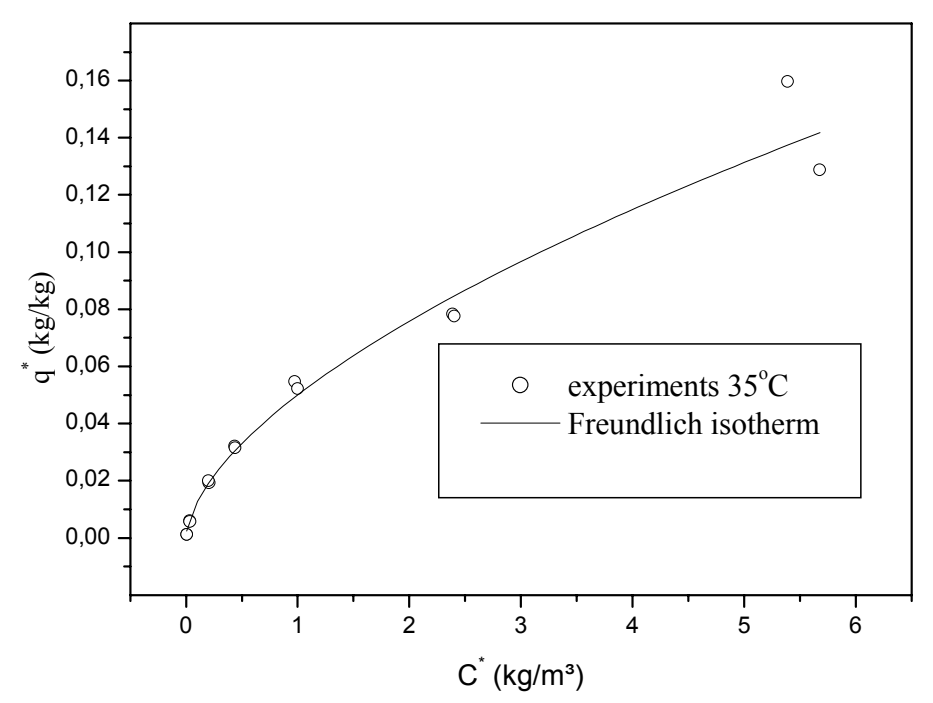

Figure 6: Adsorption isotherm data and the Freundlich adjusted model

\section{Breakthrough curves}

Figure 7 shows experimental data for the breakthrough phenomena at $308 \mathrm{~K}$, together with predictions of equation (15), based on Chern and Chien's (2002) constant-pattern concentration wave model and using the Freundlich isotherm. The effects of flow rate and bed depth were investigated.

Operational variables, physical properties and other parameters required by the breakthrough curve model, equation (15), are specified in Table 3.

As shown in Figure 7, model predictions are very good for the lower flow rates $\left(3.1 \times 10^{-8}\right.$ and $5.2 \times 10^{-8}$ $\left.\mathrm{m}^{3} / \mathrm{s}\right)$. For higher flow rates $\left(8.2 \times 10^{-8}\right.$ and $1.2 \times 10^{-7}$ $\mathrm{m}^{3} / \mathrm{s}$ ), predictions are also satisfactory, except for the early stages of adsorption where predicted curves failed to go through the origin as they should. However, notice that curves corresponding to higher flow rates are too steep for practical use: the time corresponding to the break point would be too short, making the process unviable economically. The first two breakthrough curves showed unequivocally that $\mathrm{XAD}^{\mathrm{TM}} 4$ is a suitable adsorbent for removing phenol from water solutions.

Helfferrich and Carr (1993) proved that when the adsorption rate is controlled by the mobile phase (i.e., the mass transfer rate of adsorbate in the liquid is slow) the concentration wave front has a sharp tail. On the other hand, if adsorption rate is controlled by the stationary phase (i.e., adsorption rate by the adsorbent is slow), the concentration wave tail has a sharp front. The breakthrough curves shown in Figure 7 don't fit in either of these extreme cases, meaning that adsorption rate control in our experiments was shared by the mobile and stationary phases. 
Table 3: Operational variables, physical properties and parameters used in the breakthrough curve model

\begin{tabular}{|l|r|r|r|r|}
\hline Run & $\mathbf{1}$ & $\mathbf{2}$ & $\mathbf{3}$ & $\mathbf{4}$ \\
\hline $\mathrm{C}_{\mathrm{i}}\left(\mathrm{Kg} / \mathrm{m}^{3}\right)$ & $0.492 \times 10^{-3}$ & $0.492 \times 10^{-3}$ & $0.492 \times 10^{-3}$ & $0.492 \times 10^{-3}$ \\
$\varepsilon$ & 0.56 & 0.56 & 0.56 & 0.56 \\
$\rho\left(\mathrm{kg} / \mathrm{m}^{3}\right)$ & 520 & 520 & 520 & 520 \\
$\mathrm{H}(\mathrm{m})$ & 0.059 & 0.098 & 0.073 & 0.087 \\
$\mathrm{u}(\mathrm{m} / \mathrm{s})$ & $2.34 \times 10^{-4}$ & $3.92 \times 10^{-4}$ & $6.18 \times 10^{-4}$ & $9.04 \times 10^{-4}$ \\
$\mathrm{~T}(\mathrm{~K})$ & 299 & 299 & 299 & 299 \\
$\tau_{1 / 2}(\mathrm{~s})$ & 13434 & 13434 & 6438 & 4348 \\
$\mathrm{~K}_{\mathrm{L}} \mathrm{a}\left(\mathrm{s}^{-1}\right)$ & 0.44 & 0.61 & 0.62 & 0.82 \\
\hline
\end{tabular}

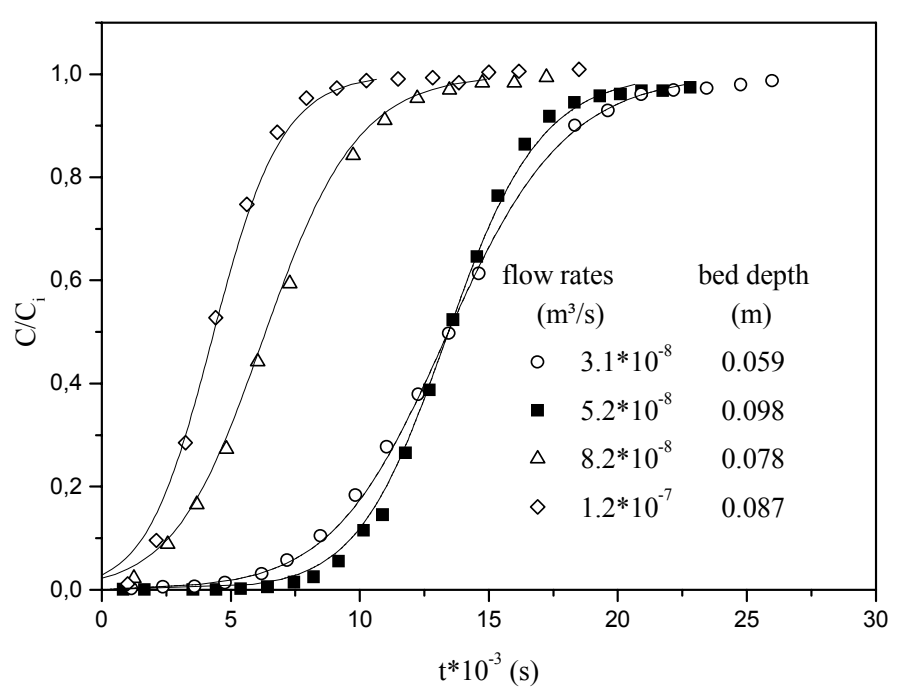

Figure 7: Breakthrough curves for adsorption of phenol onto XAD 4 resin at $299 \mathrm{~K}$ - data versus model predictions

\section{Fluidized Bed}

Figure 8 shows the classic plot of bed height $(\mathrm{H})$ versus superficial velocity (U) for both increasing and decreasing flow rates of water. According to established convention, minimum fluidization velocity is defined by the intercept of the horizontal line representing the fixed bed height for a bed that has just been defluidized and the extension of the inclined line corresponding to the fall in fluidized bed height for decreasing flow rates.

The minimum fluidization velocity $\left(\mathrm{U}_{\mathrm{mf}}\right)$ can be read directly from the above diagram, which gives $\mathrm{U}_{\mathrm{mf}} \cong 0.1 \mathrm{~m} / \mathrm{s}$.

As already mentioned, adsorption tests with the fluidized bed were carried out using a fluidizing velocity $\left(\mathrm{U}_{\mathrm{f}}\right)$ arbitrarily specified as $1.20 \mathrm{U}_{\mathrm{mf}}$. In practice the fluidizing velocity is chosen to expand the bed to a large enough extent to avoid bed clogging. Both concentration and particle size distribution of the incoming suspended solids affect this choice.

One single clogging test was made using water to fluidize the capsules and wood sawdust to simulate solid suspended materials. After running for one hour in closed circuit at $1.20 \mathrm{U}_{\mathrm{mf}}$, a number of capsules were examined. To the naked eye, no dust particle was found blocking screen openings.

Figure 9 shows the time profile of phenol concentration in the circulating liquid of the closed circuit fluidized bed (CCFB) adsorption system developed in this work.

Notice that phenol concentration after around $1200 \mathrm{~s}$ (20 min) practically didn't change, suggesting that a condition near adsorption equilibrium was achieved in the system. Notice also that initial phenol concentration had a minor effect on the time required to achieve this condition.

Table 4 allows comparing phenol concentrations in the liquid after a number of passages through the fluidized bed, with the values predicted by the model, i.e., equations (18), (19) and (20). 


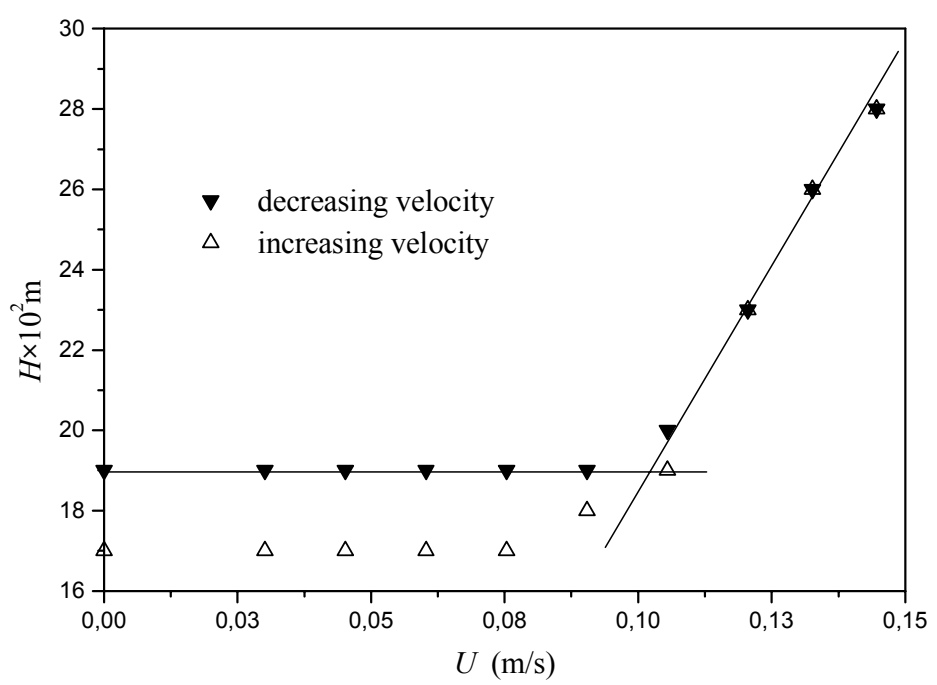

Figure 8: Determination of the minimum fluidization velocity

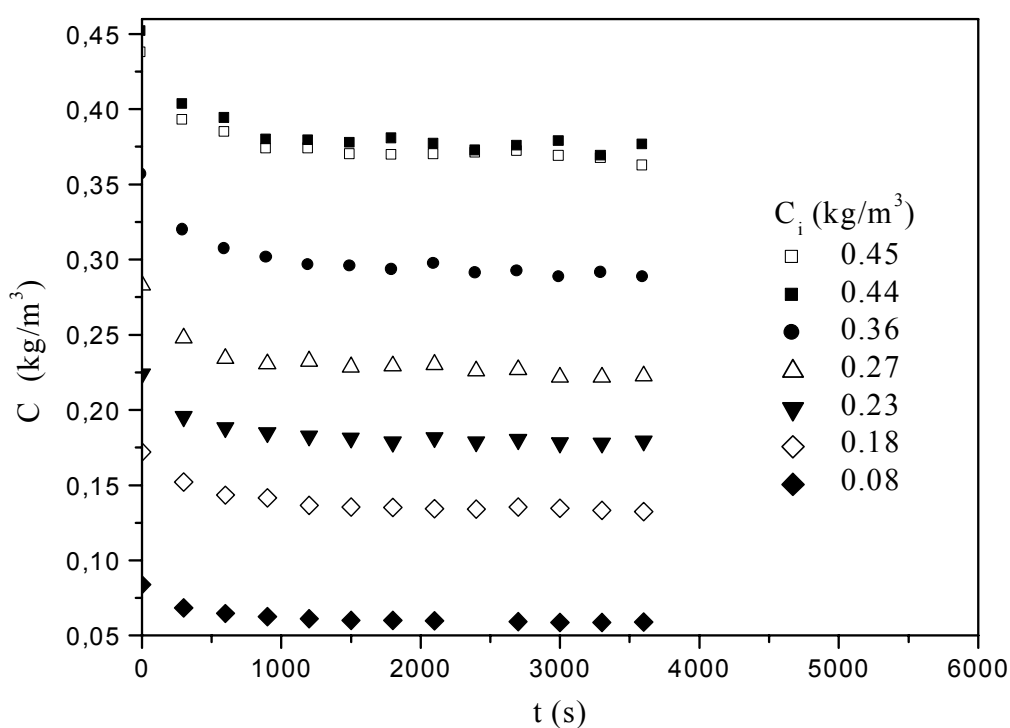

Figure 9: Phenol concentration in the circulating liquid versus time List of tables

Table 4: Data and model predictions for phenol concentration in the closed circuit fluidized bed experiments

\begin{tabular}{|c|c|c|c|c|c|c|c|}
\hline \multirow{2}{*}{$\begin{array}{c}\mathrm{C}_{\mathrm{i}} \\
\left(\mathrm{kg} / \mathrm{m}^{3}\right)\end{array}$} & \multicolumn{5}{|c|}{$\begin{array}{l}\text { Phenol concentration }\left(\mathrm{kg} / \mathrm{m}^{3}\right) \text { after } \mathrm{N} \text { passages through the closed circuit } \\
\text { fluidized bed }\end{array}$} & \multirow{2}{*}{$\begin{array}{c}C^{*} \\
\left(\mathrm{~kg} / \mathrm{m}^{3}\right) \\
(\operatorname{model}) \\
\end{array}$} & \multirow{2}{*}{$\begin{array}{c}\text { Error (\%) } \\
\text { at } \\
\mathrm{N}=101 \\
\end{array}$} \\
\hline & $\mathrm{N}=13$ & $\mathrm{~N}=25$ & $\mathbf{N}=38$ & $\mathbf{N}=\mathbf{5 0}$ & $\mathrm{N}=101$ & & \\
\hline 0.45 & 0.40 & 0.39 & 0.38 & 0.38 & 0.37 & 0.35 & -5.4 \\
\hline 0.44 & 0.39 & 0.38 & 0.37 & 0.37 & 0.37 & 0.35 & -5.4 \\
\hline 0.36 & 0.32 & 0.31 & 0.30 & 0.30 & 0.29 & 0.28 & -3.4 \\
\hline 0.28 & 0.25 & 0.23 & 0.23 & 0.23 & 0.23 & 0.21 & -8.7 \\
\hline 0.22 & 0.20 & 0.19 & 0.18 & 0.18 & 0.18 & 0.16 & -11.1 \\
\hline 0.17 & 0.15 & 0.14 & 0.14 & 0.14 & 0.13 & 0.12 & -7.7 \\
\hline 0.08 & 0.07 & 0.06 & 0.06 & 0.06 & 0.06 & 0.05 & -16.6 \\
\hline
\end{tabular}


Data shown in Table 4 corroborate the conclusions already drawn from Figure 9: after a number of passages between 25 and 38, a quasiequilibrium condition was attained with little influence of the initial phenol concentration. In all instances, the model underpredicted equilibrium concentrations. At the high initial phenol concentration levels, where uncertainties in chemical analysis are small, model predictions were considered very satisfactory (deviations in the range of $3.4-5.4 \%$ ). For mid and low concentrations, model predictions were considered just reasonable (deviations in the range of $8.7-16.6 \%$ ). However, it is important to remember that the model is very simple and reliable: it is based on a straight forward material balance of phenol and on the accuracy of the Freundlich isotherm in representing adsorption equilibrium. Errors, human and instrumental, are introduced mainly via measurements.

\section{CONCLUSIONS}

Based on developments made and experimental evaluations carried out in this work, the following conclusions are drawn:

Liquid permeable capsules containing $\mathrm{XAD}^{\mathrm{TM}} 4$ resin were developed and successfully tested for adsorption of phenol from water solutions in a closed circuit fluidized bed operating at $308 \mathrm{~K}$.

Within uncertainties of spectrophotometric analyses, a condition of quasi-adsorption equilibrium was achieved after 25 to 38 passages of the circulating liquid through the capsules' fluidized bed. The initial concentrations of phenol tested had a small effect on the number of passages required to attain this condition.

After concluding the experiments, one capsule was opened. Resin particles were then examined under an estereoscope. No breakage or surface wear was observed.

Suspended solids, a common cause of fixed bed clogging, were simulated with wood sawdust with typical particle size range and concentration. Under examination with the naked eye, capsules didn't show any blockage of screen openings.

The adsorption process was modeled using the Freundlich isotherm, producing a transcendental equation for the phenol equilibrium concentration whose values were slightly underpredicted by the model.

Chern and Chien's (2002) constant pattern concentration wave model coupled to the Freundlich isotherm successfully described the experimental

breakthrough curves for $\mathrm{XAD}^{\mathrm{TM}} 4$ resin. The effectiveness of $\mathrm{XAD}^{\mathrm{TM}} 4$ for adsorption of phenol from aqueous solutions was fully confirmed by our data.

\section{ACKNOWLEDGMENTS}

R. A. Corrêa acknowledges the Instituto de Engenharia Nuclear - CNEN/MCT for its support of this research, with special thanks to José Waldemar S. D. Cunha and Glória R. W. Silva.

\section{NOMENCLATURE}

\section{Latin Letters}

C

$\mathrm{C}^{*}$

$\mathrm{C}_{\mathrm{a}}$

$\mathrm{C}_{\mathrm{F}}$

$\mathrm{C}_{\mathrm{i}}$

$\mathrm{D}_{\mathrm{S}}$

$\mathrm{D}_{\mathrm{Z}}$

f

f

$\mathrm{H}$

$\mathrm{k}$

$\mathrm{K}_{\mathrm{L}}$

M

n

$\mathrm{N}$ interfacial mass transfer area per unit volume of bed, actual concentration of adsorbate in the liquid inside bed, concentration of adsorbate in the liquid that would be in equilibrium with q, actual concentration of adsorbate in the solid inside bed, concentration of adsorbate in the liquid at feeding, initial concentration of adsorbate in the liquid inside conical flasks, effective axial diffusion coefficient of adsorbate in the liquid inside bed,

function linking equilibrium concentrations of adsorbate $\mathrm{q}^{*}$ and $\mathrm{C}$,

function linking equilibrium concentrations of adsorbate

$$
\mathrm{C}^{*} \text { and } \mathrm{q} \text {, }
$$

bed height, empirical constant in the Freundlich isotherm, overall liquid phase mass transfer coefficient, initial mass of adsorbent inside conical flasks, empirical constant in the Freundlich isotherm, number of passages of circulating liquid through

$$
\begin{aligned}
& \mathrm{m}^{2} / \mathrm{m}^{3} \\
& \mathrm{~kg} / \mathrm{m}^{3} \\
& \mathrm{~kg} / \mathrm{m}^{3} \\
& \mathrm{~kg} / \mathrm{m}^{3} \\
& \mathrm{~kg} / \mathrm{m}^{3} \\
& \mathrm{~kg} / \mathrm{m}^{3} \\
& \begin{array}{r}
\mathrm{m} \\
\mathrm{m}^{2} / \mathrm{s}
\end{array}
\end{aligned}
$$

$\mathrm{kg} / \mathrm{kg}$

$$
\mathrm{kg} / \mathrm{m}^{3}
$$

$m$ $\mathrm{kg}_{\mathrm{p}}^{1-\mathrm{n}} \mathrm{m}_{\mathrm{s}}^{3 \mathrm{n}} / \mathrm{kg}_{\mathrm{r}}$ $\mathrm{m} / \mathrm{s}$ $\mathrm{kg}$

dimensionless dimensionless 
the fluidized bed,

q actual concentration of adsorbate in the solid inside bed,

$\mathrm{q}^{*} \quad$ concentration of adsorbate

in the solid that would be in equilibrium with $\mathrm{C}$,

$\mathrm{q}_{\mathrm{F}}^{*} \quad$ concentration of adsorbate in the solid that would be in equilibrium with $\mathrm{C}_{\mathrm{F}}$,

$\mathrm{Q}$ volume flow rate,

$\mathrm{r}^{2} \quad$ determination coefficient associated with data fitting,

$\mathrm{T}$ temperature,

$t_{1 / 2} \quad$ time required for the concentration of adsorbate in the bed effluent to rise to $\mathrm{C}_{\mathrm{F}} / 2$,

$\mathrm{u} \quad$ superficial velocity in fixed beds,

$\mathrm{u}_{\mathrm{w}} \quad$ velocity of the adsorbate concentration wave,

U superficial fluidization velocity,

$\mathrm{U}_{\mathrm{f}} \quad$ superficial velocity,

$\mathrm{U}_{\mathrm{mf}} \quad$ minimum fluidization superficial velocity,

$\mathrm{V}_{\text {liq }} \quad$ initial volume of solution inside conical flasks,

$\mathrm{X}$ relative concentration of adsorbate in the bed effluent, defined as $\mathrm{C} / \mathrm{C}_{\mathrm{F}}$,

$\mathrm{z} \quad$ upward vertical axial distance inside fixed bed,

\section{Greek Letters}

$\alpha \quad$ constant defined by equation (19),

$\beta \quad$ constant defined by equation (20),

$\varepsilon \quad$ porosity of fixed bed,

$\rho$ density of adsorbent bed,

$\rho_{a}$ density of adsorbent,

$\tau \quad$ adjusted time defined by equation (9),

$\mathrm{kg}_{\mathrm{p}}^{\mathrm{n}-1} / \mathrm{m}_{\mathrm{s}}^{\mathrm{n}}$

$$
\mathrm{kg}_{\mathrm{p}}^{\mathrm{n}} / \mathrm{m}_{\mathrm{s}}^{3 \mathrm{n}}
$$

dimensionless $\mathrm{kg} / \mathrm{m}^{3}$ $\mathrm{kg} / \mathrm{m}^{3}$

\section{Subscripts}

$\begin{array}{ll}\text { a } & \text { adsorbate } \\ \text { i } & \text { initial } \\ \text { f } & \text { fluidization } \\ \text { F } & \text { feed }\end{array}$

L liquid

$\mathrm{mf}$ minimum fluidization

$(-)$

$(-)$

dimensionless$$
\mathrm{S}
$$

K

$\mathrm{m} / \mathrm{s}$

$\mathrm{m} / \mathrm{s}$

$\mathrm{m} / \mathrm{s}$

$\mathrm{m} / \mathrm{s}$

$\mathrm{m} / \mathrm{s}$

$\mathrm{m}^{3}$

Chern, J.M. and Chien, Y.W., Adsorption of nitrophenol onto activated carbon: Isotherms and breakthrough curves, Water Research, 36, 647655 (2002).

Cooney, D.O., Adsorption Design for Wastewater Treatment, Lewis Publishers, Boca Raton (1999).

Fox, C.R., Plant uses prove phenol recovery with resins, Hydrocarbon Processing, November, 269273 (1978).

Gusler, G.M., Browne, T.E. and Cohen, Y., Sorption of organics from aqueous solutions onto polymeric resins, Ind. Eng. Chem. Res., 32, 27272735 (1993).

Helfferrich, F.G. and Carr, P.W., Non-linear waves in chromatography I - waves, shocks and shapes, Journal of Chromatography, 629, 97-122 (1993).

Hines, A.L. and Maddox, R.N., Mass Transfer Fundamentals and Applications, Prentice-Hall, Englewood Cliffs, N.J. (1985).

Knaebel, K., The basics of adsorbers design, Chemical Engineering, April, 92-101 (1999).

$\mathrm{Ku}, \mathrm{Y}$. and Lee, K.C., Removal of phenols from aqueous solution by XAD-4 Resin, Journal of Hazardous Materials, B80, 59-68 (2000).

Kunii, D. and Levenspiel, O., Fluidization Engineering, John Wiley and Sons, Inc., New York (1969).

McCabe, W.L., Smith, J.C. and Harriott, P., Unit Operations of Chemical Engineering, $6^{\text {th }}$ ed., McGraw-Hill, Inc., New York (2001).

Mijangos, F. and Navarro, A., Parametric analysis of phenol adsorption onto polymeric adsorbents, J. Chem. Eng. Data, 40, 875-879 (1995).

Navarro, A. and Mijangos, F., Análisis de la adsorción de fenoloes sobre una resina polimérica no polar, AFINIDAD LII, Noviembre Diciembre, 387-392 (1995).

Paleos, J., Adsorption from aqueous and non aqueous solutions on hydrophobic and hydrophilic high surface area copolymers, Journal of Colloid and Interface Science, 31, 1, 7-18 (1969). 
Rohm and Haas Company, Product Data Sheet 0556 A, June (2001).

Sherwood, T.K., Pigford, R.L. and Wilke, C.R., Mass Transfer, McGraw-Hill, Inc., New York (1975).

Veeraraghavan, S., Fan, L.T. and Mathews, A.P., Modeling adsorption in liquid-solid fluidized beds, Chemical Engineering Science, 44, 10, 2333-2344 (1989).

Wagner, K. and Schulz, S., Adsorption of phenol, chlorophenols, and dihydroxybenzens onto unfunctionalized polymeric resins at temperatures from $294.15 \mathrm{~K}$ to $318.15 \mathrm{~K}$, J. Chem. Eng. Data,
46, 322-330 (2001).

Zha, F.F., Fane, A.G. and Fell, C.J.D., Phenol removal by supported liquid membrane, Separation Science and Technology, 29, 17, 2317-2343 (1994).

Note

A patent application for the encapsulation of light particulate materials for the purpose of contacting fluids and solids in fluidized beds is pending at INPI - Ministério do Desenvolvimento, Indústria e Comércio Exterior, Brazil. 